Eur. J. Clin. Chem. Clin. Biochem.

Vol. 32, 1994, pp. 741-744

(C) 1994 Walter de Gruyter \& Co. Berlin - New York

\title{
Ethanol Induced Oxidative Stress and Membrane Injury in Rat Erythrocytes
}

\author{
By Eser Yıldırım Sözmen, Tijen Tanyalçin, Taner Onat, Fatma Kutay and Sermet Erlaçin \\ Ege University School of Medicine, Department of Biochemistry, Bornova-Izmir/Turkey
}

(Received November 2, 1993/July 6, 1994)

Summary: The aim of this study was to observe membrane injury and to investigate the mechanism of antioxidant defence systems against acute ethanol toxicity. Erythrocyte superoxide dismutase and $\mathrm{Na}^{+}, \mathrm{K}^{+}$-ATPase activities were significantly decreased and catalase levels were significantly increased one hour after ethanol intoxication of male swiss albino rats. These data demonstrated that superoxide dismutase and catalase are susceptible to lipid peroxidation and that these enzymes protect tissues from free radicals. The possible mechanism involved in $\mathrm{Na}^{+}$, $\mathrm{K}^{+}$-ATPase and $\mathrm{Ca}^{2+}$-ATPase inhibition are discussed in relation to the development of ethanol toxicity and the role of lipid peroxidative processes.

\section{Introduction}

One of the most frequently encountered types of chemically induced tissue injury in man is alcoholic liver disease (1). Recently, it was proposed that ethanol toxicity involves free radicals, constituting evidence for increased lipid peroxidation during ethanol poisoning $(2-5)$. Stimulation of lipid peroxidation in liposome membranes and in subcellular organelles has been shown to increase membrane rigidity. In addition to changes in fluidity, lipid peroxidation causes an increase in ionic permeability and affects the surface potentials of the membranes (4). It is known that the viability of erythrocytes depends in large part on the functional state of its active sodium and potassium transport system, which in turn depends on the structural integrity of the membrane (6). A growing body of evidence indicates that the fluidity of the lipid environment influences the activity of the physiologically important membrane enzyme, $\mathrm{Na}^{+}, \mathrm{K}^{+}$-ATPase ${ }^{1}$ ) (7).

\footnotetext{
') Enzymes:

ATP phosphohydrolase, EC 3.6.1.4

$\mathrm{Na}^{+}, \mathrm{K}^{+}, \mathrm{Mg}^{2+}$ dependent ATPase

$\mathrm{Mg}^{2+}$ dependent ATPase

$\mathrm{Ca}^{2+}$ ATPase

Superoxide dismutase, EC 1.15.1.1

Catalase, EC 1.11.1.6
}

In this communication, we report experiments to identify the effects of acute ethanol intoxication on red cell membrane lipid composition, $\mathrm{Na}^{+}, \mathrm{K}^{+}$-ATPase, and the activities of superoxide dismutase ${ }^{1}$ ) and catalase $^{\mathrm{l}}$ ) in haemolysates.

\section{Materials and Methods}

\section{Animals}

Two months old male Swiss albino rats weighing 180-220 g were used in these experiments. They were fed with standard pelleted diet and tap water ad libitum.

The ethanol group $(n=6)$ received a solution of ethanol in water, volume fraction 0.5 , by gavage in a dose of $3 \mathrm{~g} / \mathrm{kg}$ body weight in 3 minutes. The control group $(n=6)$ received water alone.

\section{Sampling}

Fifty minutes after ethanol administration, blood samples were taken by left ventricle puncture into EDTA-containing centrifuge tubes. After separation of plasma, the packed erythrocytes ivere washed two times $9 \mathrm{~g} / 1 \mathrm{NaCl}$ solution and haemolysed with icecold water.

\section{Enzyme assays}

Superoxide dismutase and catalase activities were determined immediately in haemolysates. The haemoglobin values of these haemolysates were determined with Drabkin's method. Superoxide dismutase activities were measured according to Missa \& Fridov- 
ich based on the inhibition of autoxidation of epinephrine by superoxide dismutase at $480 \mathrm{~nm}$ in a LKB Ultraspec 2 spectrophotometer. The level of enzyme that causes $50 \%$ inhibition of epinephrine autoxidation is defined as 1 unit $(8,9)$. Catalase levels were determined as described by Aebi. The catalase-mediated decomposition of $\mathrm{H}_{2} \mathrm{O}_{2}$ was followed directly at $240 \mathrm{~nm}$. One unit of catalase activity is defined as the level of enzyme required to decompose $1 \mu \mathrm{mol} \mathrm{H}_{2} \mathrm{O}_{2}$ in 1 minute $(10-12)$. Aspartate amino transferase and alanine aminotransferase activities of plasma samples were measured in a Hitachi 705 autoanalyser.

\section{Membrane preparation}

Red cell membranes were prepared according to Beutler \& Wood (13). The packed ghosts were freeze-thawed 3 times and stored at $-70^{\circ} \mathrm{C}$ until assay. Protein determinations were performed according to Lowry et al. (14).

\section{$\mathrm{Na}^{+}, \mathrm{K}^{+}-\mathrm{ATPase}$ assay}

The standard medium for total ATPase was used and the assay was performed according to Muriel \& Mourelle (7). $\mathrm{Mg}^{2+}$-activated ATPase was measured in an identical medium that included $1 \mathrm{mmol} / \mathrm{l}$ ouabain. The difference between the two reactions represented $\mathrm{Na}^{+}, \mathrm{K}^{+}$-ATPase. Inorganic phosphate was determined by the vanadate-molybdate method. $\mathrm{Ca}^{2+}$-ATPase activity was determined according to Muriel \& Mourelle (7).

\section{Lipid assays}

Lipids were extracted according to the modified method of Folch (15). An antioxidant, 2,6 di-tert-butyl-4-methyl phenol, was added at a concentration of $5 \mathrm{mg} / \mathrm{l}$ to all solvents as described by Pohl et al. (16). After the extraction with chloroform-methanol, the lower phase was filtered. Following evaporation, the lipid residue was used for phospholipid phosphorus and cholesterol determinations. Phospholipid phosphorus was determined by colorimetric molybdate and vanadate reaction, and cholesterol was determined by the Liebermann-Buchardt reaction.

\section{Reagents}

All reagents were analytical grade and purchased from Sigma Chem. Co (St. Louis) and Merck Darmstadt (Germany).

\section{Liver examination}

The livers were excised, the liver slices were fixed in buffered formalin and stained with haematoxylin eosin for histopathological examination. Liver homogenates in phosphate-buffered solution were used to determine the aspartate aminotransferase and alanine aminotransferase activities.

\section{Results}

Table 1 shows the results for osmotic fragility of erythrocytes in the control and acute ethanol-treated groups. Erythrocyte fragility was increased in the acute ethanol group. The cholesterol/phospholipid molar ratio was increased after acute ethanol administration, due to an increased cholesterol content. As seen in table 2, there was a significant decrease in $\mathrm{Na}^{+}, \mathrm{K}^{+}$-ATPase activity $(p<0.05)$ and superoxide dismutase activity $(p<0.01)$. Catalase levels increased two fold when compared with the control group $(p<0.01)$. We also found a non-significant decrease in the activity of $\mathrm{Ca}^{2+}$. ATPase. Histo-pathological examination of the livers showed no difference between the ethanol-treated and control groups under light microscopy. Liver homogenate and plasma aspartate aminotransferase and alanine aminotransferase activities were the same in both groups (tab. 3).

\section{Discussion}

There are conflicting reports on the ability of acute ethanol administration to induce hepatic lipid peroxidation $(2,4,17)$. Ingestion of ethanol causes considerable metabolic dearrangement as well as changes in the structure and function of hepatocellular organelles $(18-20)$. Typical of such changes are those affecting the ultrastructure of the hepatic plasma membrane and its associated enzyme activities such as $\mathrm{Na}^{+}, \mathrm{K}^{+}$-ATPase (21). Another proposed mechanism of ethanol toxicity is based on the involvement of free radicals. Free radical mechanisms are now well recognized as bẹing involved in several types of toxic liver damage. Several authors have presented evidence for increased lipid peroxidation during ethanol poisoning $(2,3,17)$.

We found a two fold increased activity of catalase in livers from ethanol-treated animals. It has been reported that ethanol is oxidized in the liver by three different enzyme systems: alcohol dehydrogenase, the microsomal ethanol oxidizing system and catalase (22). Koechling et al. found a relationship between blood catalase activity and alcohol consumption in a human population and they suggested that catalase activity measurement would be a strong positive determinant of alcohol intake (23). On the other hand, Bradford et al. demonstrated that catalase is the prodominant enzyme of alcohol metabolism in mice treated with the alcohol dehydrogenase inhibitor, 4-methylpyrazole. Their results showed that while the contribution of catalase was $50 \%$ in alcohol dehydrogenase $(+)$ mutant mice at low doses of ethanol, it became $100 \%$ as the ethanol concentration was elevated (24).

We found a significant decrease in superoxide dismutase activity in the acute ethanol-treated group. Similar results were also observed by Ledig et al., who reported a decrease of superoxide dismutase activity following the intraperitoneal injection of ethanol (17). They suggested that the inhibition of superoxide dismutase activity by ethanol may allow an accumulation of cytotoxic $\mathrm{O}_{2}$ radicals, which could partially explain the toxicity of ethanol for cellular metabolism (17): This decrease in super- 
Tab. 1 The results of osmotic fragility tests in the control and ethanol-treated groups.

\begin{tabular}{|c|c|c|c|c|}
\hline \multicolumn{2}{|l|}{ Sodium chloride } & \multicolumn{3}{|c|}{ Fraction of erythrocytes haemolysed (\%) } \\
\hline $\begin{array}{l}\text { Volume fraction of } \\
9 \mathrm{~g} / 1 \mathrm{NaCl}(\%)\end{array}$ & $\begin{array}{l}\text { Concentration } \\
(\mathrm{g} / \mathrm{l})\end{array}$ & Control group & Ethanol group & Significance \\
\hline $\begin{array}{l}30 \\
40 \\
45 \\
50 \\
55 \\
60 \\
70\end{array}$ & $\begin{array}{l}2.70 \\
3.60 \\
4.05 \\
4.50 \\
4.95 \\
5.40 \\
6.30\end{array}$ & $\begin{array}{l}94.25 \pm 0.85 \\
79.00 \pm 1.73 \\
49.50 \pm 2.50 \\
18.50 \pm 0.96 \\
1.00 \pm 0.41 \\
0 \\
0\end{array}$ & $\begin{array}{r}96.75 \pm 1.25 \\
75.75 \pm 5.89 \\
61.50 \pm 1.70 \\
26.75 \pm 2.01 \\
10.50 \pm 4.11 \\
3.00 \pm 0.41 \\
0.50 \pm 0.29\end{array}$ & $\begin{array}{l}p>0.05 \\
p>0.05 \\
p<0.01 \\
p<0.01 \\
p<0.05 \\
p<0.01 \\
p<0.05\end{array}$ \\
\hline
\end{tabular}

Data were given as the mean $\pm \mathrm{SEM}$.

Tab. 2 Effect of ethanol on erythrocyte antioxidant and membrane enzymes.

\begin{tabular}{lcccc}
\hline & Control group $(\mathrm{n}=6)$ & Ethanol group $(\mathrm{n}=6)$ & Significance \\
\hline Superoxide dismutase $(\mathrm{U} / \mathrm{gHb})$ & $7164.8 \pm 378$ & $2068 \pm 320$ & $\mathrm{p}<0.01$ \\
Catalase $(\mathrm{U} / \mathrm{gHb})$ & $5724.0 \pm 317$ & 10826 & \pm 669 & $\mathrm{p}<0.01$ \\
$\mathrm{Na}^{+}, \mathrm{K}^{+}-\mathrm{ATPase}\left(\mathrm{P}_{\mathrm{i}}, \mu \mathrm{mol} / \mathrm{h} \cdot \mathrm{mg}\right.$ protein) & $0.63 \pm 0.04$ & $0.43 \pm 0.08$ & $\mathrm{p}<0.05$ \\
$\mathrm{Ca}^{2+}-\mathrm{ATPase}\left(\mathrm{P}_{\mathrm{i}}, \mu \mathrm{mol} / \mathrm{h} \cdot \mathrm{mg}\right.$ protein) & $1.52 \pm 0.12$ & $1.43 \pm$ & 0.10 & $\mathrm{p}>0.05$ \\
$\mathrm{Cholesterol} / \mathrm{phospholipid} \mathrm{molar}$ ratio & $0.52 \pm 0.22$ & $0.72 \pm 0.12$ & $\mathrm{p}>0.05$ \\
Cholesterol $(\mu \mathrm{mol} / \mathrm{mg}$ protein) & $0.28 \pm 0.03$ & $0.36 \pm 0.06$ & $\mathrm{p}>0.05$ \\
Phospholipid $(\mu \mathrm{mol} / \mathrm{mg}$ protein) & $0.45 \pm$ & 0.04 & $0.49 \pm 0.05$ & $\mathrm{p}>0.05$ \\
\hline
\end{tabular}

Data were given as the mean $\pm \mathrm{SEM}$.

Tab. 3 The activities of liver marker enzymes in plasma and liver homogenates of control and ethanol-treated animals.

\begin{tabular}{llrr}
\hline & & $\begin{array}{l}\text { Control group } \\
(\mathrm{n}=6)\end{array}$ & $\begin{array}{c}\text { Ethanol group } \\
(\mathrm{n}=6)\end{array}$ \\
\hline Plasma aspartate aminotransferase & $(\mathrm{U} / \mathrm{l})$ & $123.30 \pm 8.21$ & $104.50 \pm 3.32$ \\
Plasma alanine aminotransferase & $(\mathrm{U} / \mathrm{l})$ & $44.10 \pm 3.30$ & $41.80 \pm 4.23$ \\
Liver aspartate aminotransferase & $(\mathrm{U} / \mathrm{mg}$ protein) & $1.23 \pm 0.11$ & $1.47 \pm 0.21$ \\
Liver alanine aminotransferase & (U/mg protein) & $0.76 \pm 0.11$ & $0.72 \pm 0.07$ \\
\hline
\end{tabular}

oxide dismutase activity might be due to inactivation of the enzyme by the increased concentration of hydroxy radicals arising from ethanol metabolism.

Free radicals can cause cellular injury when produced in amounts sufficient to overcome the normally efficient protective mechanism. Lipid peroxidation is a free radical mediated chain reaction which is enhanced as a consequence of oxidative stress, and it results in an oxidative deterioriation of membrane polyunsaturated fatty acids (25). It is known that $\mathrm{O}_{2}$ radicals inactivate $\mathrm{Na}^{+}$, $\mathrm{K}^{+}$-ATPase, as we also observed. On the other hand, fatty acyl composition and cholesterol content of the plasma membrane can also affect $\mathrm{Na}^{+}, \mathrm{K}^{+}$-ATPase activity. Since free fatty acids can alter cellular functions by their affects on transport mechanisms, it has been proposed that they alter $\mathrm{Na}^{+}, \mathrm{K}^{+}$-ATPase activity, $\mathrm{Ca}^{2+}$ movement and guanylate cyclase activity (25). In order to determine the alterations of fluidity of erythrocyte membranes due to oxidative stress, we investigated the osmotic fragility of erythrocytes. The results (tab. 1) show that haemolysis of erythrocytes from ethanoltreated rats started when the medium consisted of 6.3 $\mathrm{g} / \mathrm{l} \mathrm{NaCl}$, while haemolysis of controls started at about $4.95 \mathrm{~g} / 1 \mathrm{NaCl}$. Comporti et al. confirmed that lipid peroxidation in liver homogenates was increased by acute ethanol intoxication (26). The increased lipoperoxides can be considered as responsible, at least in part, for the red cell injury, since we observed increased osmotic fragility of erythrocytes in the acute ethanol-treated group. Peroxidative attacks on membrane proteins have been reported as responsible for both cation leakage and haemolysis. Lipid peroxidation alters membrane constituents and affects their interactions in such a way that membrane microviscosity and fluidity are also altered. In ethanol-treated rats we found an increase in the cholesterol/phospholipid molar ratio due to an increased 
cholesterol content, although the change was not statistically significant. Some investigators have reported an increase in the cholesterol content of erythrocyte membranes in animals treated with ethanol $(27,28)$. Although chronic ethanol administration causes an increase in acyl CoA-cholesterol acyltransferase, the enzyme responsible for the intracellular production of cholesteryl esters (29), the mechanism of increase in membrane cholesterol in acute ethanol ingestion is still obscure.

We therefore suggest that several pathological processes are related to the membrane alterations that occur after acute ethanol administration, even when there is no histopathological evidence of cell injury. We consider it highly probable that lipid peroxidation is an initiating factor in the pathogenesis of membrane injury.

\section{References}

1. Ryle, P. R. (1984) Free radicals, lipid peroxidation and ethanol hepatotoxicity. Lancet 25,461 .

2. Dianzani, M. U. (1985) Lipoperoxidation in ethanol poisoning: A critical reconsideration. Alcohol \& Alcoholism 20, 161173.

3. Nordmann, R., Ribiere, C. \& Rouach, H. (1990) Ethanol-induced lipid peroxidation and oxidative stress in extrahepatic tissues. Alcohol \& Alcoholism 25, 231-237.

4. Poli, G., Albano, E. \& Dianzani, M. U. (1987) The role of lipid peroxidation in liver damage. Chem. Phys. Lipids 45, 117-142!

5. Thomas, C. E. \& Reed, D. J. (1990) Radical-induced inactivation of kidney $\mathrm{Na}^{+}, \mathrm{K}^{+}$-ATPase; Sensitivity to membrane lipid peroxidation and the protective effect of vitamin E. Arch. Biochem. Biophys. 281, 96-105.

6. Mourelle, M. \& Franco, M. T. (1991) Erythrocyte defects precede the onset of $\mathrm{CCl}_{4}$-induced liver cirrhosis. Protection by Sylmarin. Life Sci. 48, 1083-1090.

7. Muriel, P. \& Mourelle, M. (1990) The role of membrane composition in ATPase activities of cirrhotic rat liver: Effect of Sylmarin. J. Appl. Toxicol. 10, 281-284.

8. Misra, H. P. \& Fridovich, I. (1972) The role of superoxide anion in the autooxidation of epinephrine and a simple assay for superoxide dismutase. J. Biol. Chem. 247, 3170-3175.

9. Winterbourn, C. C., Hawkins, R. E., Brian, M. \& Carrell, R. W. (1975) The estimation of red cell superoxide dismutase activity. J. Lab. Clin. Med. 85, 337-341.

10. Aebi, H. (1984) Catalase in vitro. Methods in Enzymol 105, $121-341$.

11. Agar, N. S., Sadrzadeh, M. H., Hallaway, P. E. \& Eaton, J. W. (1986) Erythrocyte catalase. J. Clin. Invest. 77, 319-321.

12. Lück, H. (1983) Catalase. In: Methods of Enzymatic Analysis (Bergmeyer, H. U., eds.) third edition, Verlag Chemie, Weinheim, Vol. III, p. 279.

13. Wood, L. \& Beutler, E. (1967) Temperature dependence of sodium-potassium activated erythrocyte adenosine triphosphatase. J. Lab. Clin. Med. 70, 287-294.

14. Lowry, O. H., Rosebrough, N. J., Farr, A. L. \& Randall, R. J. (1951) Protein measurement with the Folin phenol reagent. J. Biol. Chem. 193, 265-275.

15. Folch, J., Lees, M. \& Sloane Stanley, G. H. (1957) A simple method for the isolation of purification of total lipides from animal tissues. J. Biol. Chem. 226, 497-509.

16. Pohl, S. L., Krans, H. M. J., Kozyreff, V., Bimbaumer, L. \& Rodbell, M. (1971) The glucagon sensitive adenyl cyclase system in plasma membranes of rat liver. J. Biol. Chem. 246, $4447-4454$.

17. Ledig, M., M'Paria, J. R. \& Mandel, P. (1981) Superoxide dismutase activity in rat brain during acute and chronic alcohol intoxication. Neurochem. Res. 6, 385-390.

18. Lieber, C. S. (1984) Alcohol and the liver: 1984 update. Hepatology 4, 1243-1260.

19. Rottenberg, H., Robertson, D. E. \& Rubin, E. (1980) The effect of ethanol on the temperature dependence of respiration and ATPase activities of rat liver mitochondria. Lab. Invest. 42, $318-326$.

20. Speisky, H., Macdonald, A., Giles, G., Orrego, H. \& Israel, $Y$. (1985) Increased loss and decreased synthesis of hepatic glutathione after ethanol administration. Biochem. J. 255, $565-572$.

21. Gonzalez Calvin, J. L., Saunders, J. B., Crossley, I. R., Dickenson, C. J., Smith, H. M., Tredger, J. M. \& Williams, R. (1985) Effects of ethanol administration on rat liver plasma membrane-bound enzymes. Biochem. Pharmacol. 34, 2685-2689.

22. Seitz, H. K. \& Csomos, G. (1992) Alcohol and the liver: Ethanol metabolism and the pathomechanism of alcoholic liver damage. Orv. Hetil. 133, 3183-3189.

23. Koechling, U. M. \& Amit, Z. (1992) Relationship between blood catalase activity and drinking history in a human population, a possible biological marker of the affinity to consume alcohol. Alcohol \& Alcoholism 27, 181-188.

24. Bradford, B. U., Seed, C. B., Handler, J. A., Forman, D. T. \& Thurman, R. G. (1993) Evidence that catalase is a major pathway of ethanol oxidation in vivo: Dose-response studies in deer mice using methanol as a selective substrate. Arch. Biochem. Biophys. 303, 172-176.

25. Spector, A. A. \& Yorek, M. A. (1985) Membrane lipid composition and cellular function. J. Lipid. Res. 26, 1015-1035.

26. Comporti, M., Benedetti, A. \& Chieli, E. (1973) Studies on in vitro peroxidation of liver lipids in ethanol-treated rats. Lipids 8, 498-502.

27. Branchey, M. H. \& Buydens-Branchey, L. (1990) Are the effects of chronic ethanol administration on erythrocyte membrane mediated by changes in plasma lipids? Drug Alcohol Depend. 25, 67-71.

28. Corbett, R., Menez, J. F., Floch, H. H. \& Leonard, B. E. (1991) The effects of chronic ethanol administration on rat liver and erythrocyte lipid composition: Modulatory role of 'evening primrose oil'. Alcohol \& Alcoholism 26, 459-464.

29. Dawidowicz, E. A. (1985) The effect of ethanol on membranes. Hepatology $5,697-699$.

Eser Yıldınm Sözmen, MD, PhD

Ege University School of Medicine

Department of Biochemistry

Bornova-Izmir

Turkey 